\title{
Experimental and theoretical lifetimes and transition probabilities for spectral lines in $\mathbf{N b}$ II
}

\author{
H. Nilsson ${ }^{1}$, L. Engström ${ }^{2}$, H. Lundberg ${ }^{2}$, H. Hartman ${ }^{1,3}$, P. Palmeri ${ }^{4}$, and P. Quinet ${ }^{4,5}$ \\ ${ }^{1}$ Lund Observatory, Lund University, Box 43, 22100 Lund, Sweden \\ e-mail: hampus.nilsson@astro.lu.se \\ 2 Department of Physics, Lund University, Box 118, 22100 Lund, Sweden \\ 3 Materials Science and Applied Mathematics, Malmö University, 20506 Malmö, Sweden \\ 4 Physique Atomique et Astrophysique, Université de Mons, 7000 Mons, Belgium \\ 5 IPNAS, Université de Liège, 4000 Liège, Belgium
}

Received 4 April 2019 / Accepted 30 May 2019

\begin{abstract}
Aims. We have measured and calculated lifetimes of high lying levels in $\mathrm{Nb}$ II, and derived absolute transition probabilities by combining the lifetimes with experimental branching fractions.

Methods. The lifetimes were measured using time-resolved laser-induced fluorescence in a two-photon and two-step excitation scheme. The branching fractions were measured in intensity calibrated spectra from a hollow cathode discharge, recorded with a Fourier transform spectrometer. The calculations were performed with the relativistic Hartree-Fock method including core polarization.

Results. We report experimental lifetimes of 13 levels in the $4 \mathrm{~d}^{3}\left({ }^{4} \mathrm{~F}\right) 5 \mathrm{~d}$ and $4 \mathrm{~d}^{3}\left({ }^{4} \mathrm{~F}\right) 6 \mathrm{~s}$ subconfigurations, at an energy around $70000 \mathrm{~cm}^{-1}$. By combining the lifetimes with experimental branching fractions absolute transition probabilities of 59 lines are derived. The experimental results are compared with calculated values.
\end{abstract}

Key words. atomic data - methods: laboratory: atomic - techniques: spectroscopic

\section{Introduction}

Niobium was discovered in 1801 by the British chemist Charles Hatchett. The element was discovered in the mineral columbite, and Hatchett gave the element the name columbium $(\mathrm{Cb})$. In 1844 Heinrich Rose reported two new elements, niobium, and penopium. However, Jean-Charles de Marignac showed that the elements columbium, niobium and penopium were in fact all the same. The name columbium was in use until 1949 when niobium was adopted as the official name of element number 41 . The Swedish chemist Christian Blomstrand is believed to be the first one to isolate niobium. The fascinating history of niobium, columbium, pelopium, and tantalum and Charles Hatchett can be found in Griffith \& Morris (2003).

Niobium is a key element to understand and probe the slowneutron-capture process (the s-process). Niobium is monoisotopic $\left({ }^{93} \mathrm{Nb}\right)$ and believed to be mainly produced by $\beta$ decay of ${ }^{93} \mathrm{Zr}$, with a half-life of $\tau_{1 / 2}=1.53 \times 10^{6} \mathrm{yr}$. The probability of ${ }^{93} \mathrm{Zr}$ capturing a neutron and producing ${ }^{94} \mathrm{Zr}$ is larger than that of ${ }^{93} \mathrm{Zr}$ decaying to ${ }^{93} \mathrm{Nb}$ as long as the s-process is ongoing. Hence the niobium abundance can give the time since the s-process ended (Smith \& Lambert 1984). Furthermore, by comparing the ratios ${ }^{93} \mathrm{Zr} /{ }^{93} \mathrm{Nb}$ and ${ }^{99} \mathrm{Tc} /{ }^{99} \mathrm{Ru}$ it is possible to determine the s-process temperature and the time since the s-process started (Neyskens et al. 2015).

In 1935 Meggers \& Schribner (1935) published a paper reporting the term analysis of the first two spectra, Cb I and Cb II (arc and spark) of columbium, including 2000 lines combining 60 levels in $\mathrm{Cb}$ II. The analysis was extended by Humpreys \& Meggers (1945) who reported 183 levels in Cb II. In Iglesias (1954) a study of the vacuum ultraviolet spectrum was reported, identifying 20 new energy levels and 330 spectral lines as belonging to $\mathrm{Nb}$ II (this is the first term analysis paper using the name niobium instead of columbium). The most recent term analysis of $\mathrm{Nb}$ II is reported by Ryabtsev et al. (2000), based on spectra recorded with Fourier transform spectroscopy. A total of 353 energy levels in $\mathrm{Nb}$ II are presently known from the work reported in these papers.

Experimental transition probabilities in $\mathrm{Nb}$ II have been reported by Hannaford et al. (1985), by combining radiative lifetimes of 27 levels with branching fractions (BFs) derived from the work of Corliss \& Bozman (1962). Nilsson \& Ivarsson (2008) reported transition probabilities for 145 lines combining BFs measured in Fourier transform spectra with the lifetimes reported by Hannaford et al. (1985). In Nilsson et al. (2010) additional transition probabilities were reported for lines from the $4 d^{3} 5 p$ configuration derived from lifetimes combined with $\mathrm{BFs}$, along with new theoretical calculations.

Niobium has one stable isotope, ${ }^{93} \mathrm{Nb}$, which has an odd number of nucleons. Due to the nuclear spin $I=9 / 2$ and a large magnetic moment, $\mu=6.1705 \mu_{N}$ (Mills et al. 1988), many of the spectral lines show large hyperfine structure (hfs). Experimental measurements of hfs has been reported by Young et al. (1995) and Nilsson \& Ivarsson (2008). However, none of the lines reported in the present work are noticeably affected by hfs.

In this work we report experimental transition probabilities for 59 lines originating from 13 levels in the $4 d^{3}\left({ }^{4} F\right) 5 d$ and $4 d^{3}\left({ }^{4} F\right) 6 s$ subconfigurations, derived by combining branching fractions and radiative lifetimes. These new data are compared with semi-empirical calculations performed using a relativistic Hartree-Fock model including core-polarization effects. 


\section{Laboratory measurements}

\subsection{Lifetimes}

The spectrum and term system of $\mathrm{Nb}$ II have been thoroughly investigated by Ryabtsev et al. (2000). This work was essential not only to find the investigated levels but also to check for possible blending, as discussed below. The ground term in $\mathrm{Nb}$ II is the even $4 \mathrm{~d}^{4}{ }^{5} \mathrm{D}$, with levels between 0 and $1200 \mathrm{~cm}^{-1}$, and the second lowest even term is $4 \mathrm{~d}^{3}\left({ }^{4} \mathrm{~F}\right) 5 \mathrm{~s}{ }^{5} \mathrm{~F}$ between 2300 and $4150 \mathrm{~cm}^{-1}$. To reach the investigated high lying even $5 \mathrm{~d}$ and 6s levels, between 68000 and $73200 \mathrm{~cm}^{-1}$, we employed either two-photon excitations using a single laser or a two-step procedure where the first laser excited intermediate odd levels in the $4 d^{3}\left({ }^{4} F\right) 5 p{ }^{5} G$ term from which the second laser reached the $5 \mathrm{~d}$ and $6 \mathrm{~s}$ levels. Figure 1 illustrates the levels and wavelengths involved, and Table 1 gives the detailed excitation scheme for each level.

The experimental setup for two-photon and two-step measurements at the high-power laser facility at the University of Lund is described in detail in Engström et al. (2014) and Lundberg et al. (2016) and only the most important details will be given here. The setup includes three Nd:YAG lasers operating at $10 \mathrm{~Hz}$. The frequency-doubled output of one of them (Continuum Surelite) is focused on a rotating niobium target in a vacuum chamber with a pressure of about $10^{-4}$ mbar to produce the niobium ions through laser ablation. Interactions with the electrons in the created plasma also excite the even $4 d^{4}$ and $4 d^{3} 5$ s configurations, which contain the starting levels in our experiments.

For the two-step measurements, the second Nd:YAG (Continuum NY-82) laser pumps a dye laser (Continuum Nd-60) which, after frequency-doubling, produces a $10 \mathrm{~ns}$ long pulse for the first excitation to the odd $4 \mathrm{~d}^{3}\left({ }^{4} \mathrm{~F}\right) 5 \mathrm{p}{ }^{5} \mathrm{G}$ levels. A similar laser combination is used for the second step, but here the output of the Nd:YAG laser is temporally compressed using Brillouin scattering in water before pumping the dye laser. The frequencydoubled light from the dye laser is then passed through a tube with hydrogen gas where a Stokes shift of $4153 \mathrm{~cm}^{-1}$ could be added. The final length, full width at half maximum (FWHM), of the second step pulse was about $1 \mathrm{~ns}$.

Both laser pulses intersected the niobium plasma from the same direction at right angles to the ablation laser a few millimeter above the niobium target. The timing between the two excitations is very important and adjusted so that the second step laser coincided in time with the maximum fluorescence from the intermediate level. Because of the difference in pulse length between the two lasers this ensures that the intermediate level population is constant during the second excitation. For the two-photon measurements only the short pulses from the second laser were used.

The fluorescence from the excited levels was observed with a small $\mathrm{f} / 8$ monochromator, with its $120 \mu \mathrm{m}$ wide entrance slit parallel to the excitation lasers, in a direction perpendicular to all three laser beams. The observed line width (FWHM) was $0.5 \mathrm{~nm}$ in the second spectral order. The time varying signal was registered with a microchannel-plate photomultiplier (Hamamatsu R3809U) with a rise time of $0.15 \mathrm{~ns}$, and digitized by a Tektronix DPO 7254 oscilloscope in time intervals of $50 \mathrm{ps}$. A second channel on the oscilloscope sampled simultaneously the temporal shape of the short-pulsed (1 ns) laser obtained from a fast photodiode. Each decay curve and pulse shape was averaged over 1000 laser shots. Between 10 and 20 decay curves were recorded for each level. The lifetimes were determined by fitting a single exponential decay, convoluted by the measured shape of the second step laser, and a constant background using the

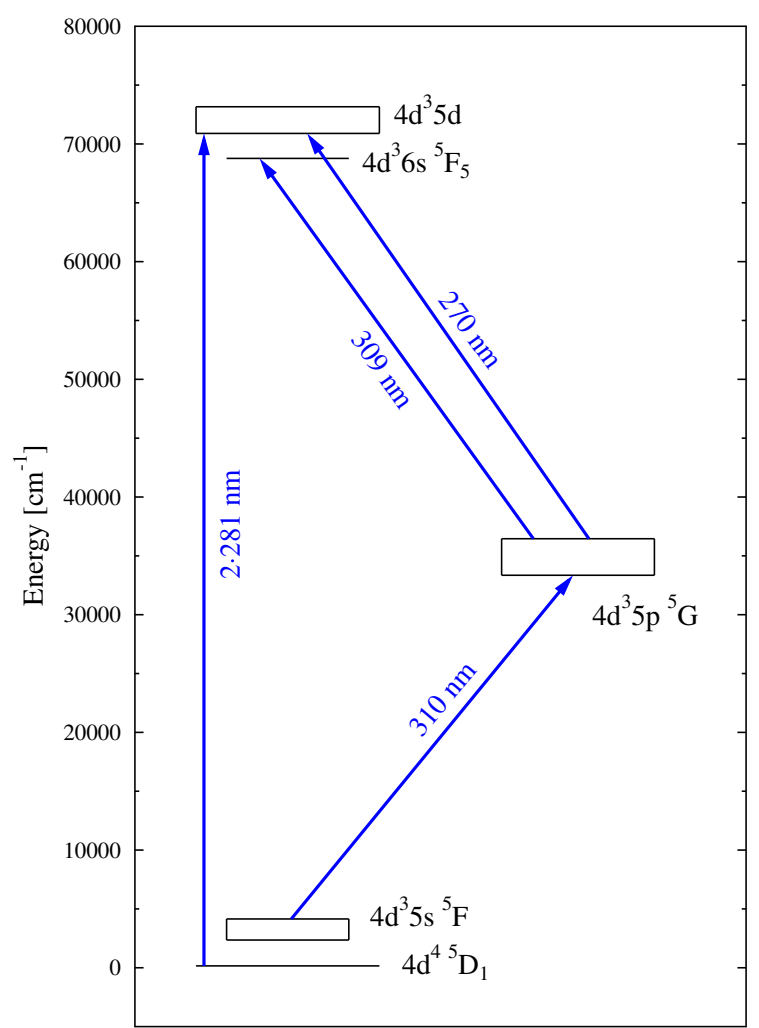

Fig. 1. Schematic term system for $\mathrm{Nb}_{\text {II }}$ showing the investigated levels and the typical wavelengths used for the two-photon and two-step excitations.

software DECFIT (Palmeri et al. 2008). In the two-photon case, the square of the measured excitation pulse was used.

In the two-step measurements some corrections of the recorded decay curves were necessary before the fitting procedure. In the case of $5 \mathrm{~d}^{5} \mathrm{H}_{6,7}$ the only sufficiently intense decay channels were the same as those used for the second step excitation. This resulted in a contamination of the decay by scattered laser light. However, this effect was taken care of by recording a decay curve for the second laser either at a wavelength slightly off resonance or with the first step laser blocked. This measurement was then subtracted from the observed primary decay before the lifetime extraction. Figure 2 illustrates this problem for $5 \mathrm{~d}^{5} \mathrm{H}_{6}$, which was the worst case observed. Another problem was encountered in most cases because the very intense and long-lived fluorescence from the intermediate level could produce a small but noticeable contribution in the measured decay channel even at substantial wavelength differences. Similar to the previous example, this could be handled by recording and subtracting the signal from the intermediate level with the second step laser blocked. Finally, for both two-photon and twostep measurements, uncorrectable blending problem may arise from cascades, that is intermediate levels being populated from the level under investigation that in turn decay with wavelengths close to the investigated decay channel. This problem precluded for example the measurement of the $5 \mathrm{~d}^{5} \mathrm{G}_{4}$ level. To search for such effects, detailed spectroscopic studies, such as the one by Ryabtsev et al. (2000), are essential.

The excitation schemes employed and the final experimental lifetimes are presented in Table 1. The quoted uncertainties are based on the variations between the repeated measurements that include tests to ascertain the absence of systematic effect. Examples of the latter effects are the variations in the lifetimes with 
H. Nilsson et al.: Experimental and theoretical lifetimes and transition probabilities for spectral lines in $\mathrm{Nb}$ II

Table 1. Experimental details and the measured and calculated lifetimes of the levels in $\mathrm{Nb}$ II.

\begin{tabular}{|c|c|c|c|c|c|c|c|c|c|}
\hline \multirow[t]{2}{*}{ Level } & \multirow[t]{2}{*}{$E^{(a)}\left[\mathrm{cm}^{-1}\right]$} & \multicolumn{2}{|c|}{ Intermediate level } & \multirow{2}{*}{$\begin{array}{c}\text { Excitation } \lambda_{\text {air }} \\
{[\mathrm{nm}]}\end{array}$} & \multirow{2}{*}{$\begin{array}{c}\lambda_{\mathrm{obs}}{ }^{(b)} \\
{[\mathrm{nm}]}\end{array}$} & \multirow[t]{2}{*}{ Method $^{(c)}$} & \multirow[t]{2}{*}{$\tau_{\exp }[\mathrm{ns}]$} & \multicolumn{2}{|c|}{$\tau_{\text {theory }}[\mathrm{ns}]$} \\
\hline & & Term & $E^{(a)}\left[\mathrm{cm}^{-1}\right]$ & & & & & This work & Kurucz $^{(d)}$ \\
\hline $6 s^{5} \mathrm{~F}_{5}$ & 68772.9 & $5 p^{5} G_{6}$ & 36455.5 & 309.3 & 325 & $2 \omega$ & $2.55 \pm 0.10$ & 2.54 & 2.79 \\
\hline $5 d^{5} \mathrm{H}_{3}$ & 70895.5 & & & 282.6 & 266 & $2 \gamma, 2 \omega$ & $1.65 \pm 0.20$ & 1.72 & 1.65 \\
\hline $5 \mathrm{~d}^{5} \mathrm{H}_{5}$ & 71684.9 & $5 p^{5} G_{4}$ & 34632.0 & 269.8 & 270,293 & $2 \omega+A S$ & $1.95 \pm 0.15$ & 1.82 & 1.76 \\
\hline $5 \mathrm{~d}^{5} \mathrm{H}_{6}$ & 72231.7 & $5 p^{5} G_{5}$ & 35474.2 & 272.0 & 272 & $2 \omega+A S$ & $1.95 \pm 0.15^{\mathrm{e}}$ & 1.86 & 1.77 \\
\hline $5 d^{5} \mathrm{H}_{7}$ & 72861.3 & $5 p^{5} G_{6}$ & 36455.5 & 274.6 & 274 & $2 \omega+A S$ & $1.75 \pm 0.10^{\mathrm{e}}$ & 1.89 & 1.77 \\
\hline $5 d^{5} G_{5}$ & 72460.7 & $5 p^{5} G_{5}$ & 35474.2 & 270.3 & 286 & $2 \omega+A S$ & $2.1 \pm 0.2$ & 2.08 & 2.02 \\
\hline $5 d^{5} G_{6}$ & 73161.1 & $5 p^{5} G_{6}$ & 36455.5 & 272.4 & 285 & $2 \omega+A S$ & $2.1 \pm 0.2$ & 2.11 & 2.05 \\
\hline $5 d^{5} \mathrm{P}_{1}$ & 70956.0 & & & 282.4 & 299 & $2 \gamma, 2 \omega$ & $2.10 \pm 0.15$ & 2.11 & 2.11 \\
\hline $5 d^{5} \mathrm{P}_{3}$ & 72125.2 & $5 p{ }^{5} G_{4}$ & 34632.0 & 266.6 & 295 & $2 \omega+A S$ & $2.00 \pm 0.15$ & 2.03 & 1.98 \\
\hline $5 d^{5} F_{1}$ & 71196.1 & & & 281.5 & 275 & $2 \gamma, 2 \omega$ & $2.20 \pm 0.15$ & 1.92 & 1.94 \\
\hline $5 d^{5} F_{3}$ & 72183.1 & $5 p^{5} G_{4}$ & 34632.0 & 266.2 & 280 & $2 \omega+A S$ & $2.00 \pm 0.15$ & 1.96 & 1.98 \\
\hline $5 d^{5} F_{4}$ & 72624.9 & $5 p^{5} G_{5}$ & 35474.2 & 269.1 & 285 & $2 \omega+A S$ & $2.00 \pm 0.15$ & 1.98 & 1.95 \\
\hline $5 d^{5} F_{5}$ & 73115.4 & $5 p^{5} G_{6}$ & 36455.5 & 272.7 & 285 & $2 \omega+A S$ & $1.95 \pm 0.15$ & 2.00 & 1.96 \\
\hline
\end{tabular}

Notes. ${ }^{(a)}$ Ryabtsev et al. (2000). ${ }^{(b)}$ All fluorescence measurements were performed in the second spectral order. ${ }^{(c)} 2 \omega$ means the second harmonic of the dye laser, AS means one added Stokes shift $\left(4153 \mathrm{~cm}^{-1}\right)$ and $2 \gamma$ means two-photon excitation. ${ }^{(d)}$ Semi-empirical superpositionof-configurations calculation by Kurucz (2017). ${ }^{(e)}$ Corrected for scattered light from the second step laser.

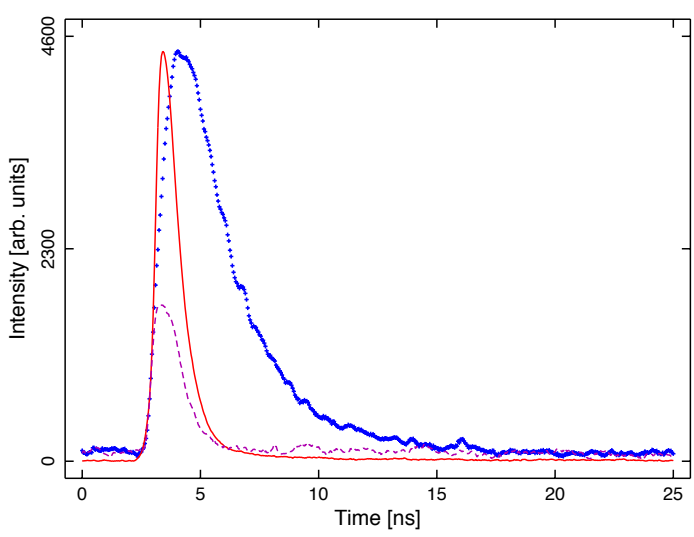

Fig. 2. Measured decay curve for the $4 \mathrm{~d}^{3} 5 \mathrm{~d}{ }^{5} \mathrm{H}_{6}$ level (+) and the recorded second step laser pulse (-). The dashed curve is a recording of the scattered light from the second step laser at a slightly detuned wavelength. This measurement is then subtracted from the real decay before the lifetime determination. The actual measurement extends to $40 \mathrm{~ns}$.

and without the small correction for the background contribution from the intermediate levels, discussed above, and the search for saturation effects by inserting a varying number of neutral density filters in the second step laser beam. Furthermore, possible flight effects (Sikström et al. 2002) were investigated by varying the delay between the ablation and excitation lasers, which results in ions with different velocities arriving in the interaction zone at a fixed distance from the target.

\subsection{Branching fractions and transition probabilities}

The branching fraction (BF) of a line is defined as the transition probability of the line divided by the sum of transition probabilities for all lines from the same upper level, that is the inverse of the lifetime $(\tau)$. Hence, if one can measure the intensity of all transitions from one upper level, transition probabilities can be derived by combining the BFs with radiative lifetimes according to $B F_{u l}=I_{u l} / \sum_{k=1} I_{u k}$ and $A_{u l}=B F_{u l} / \tau_{u}$. To convert the transition probabilities to oscillator strengths $(f)$, the following relation can be used: $g_{l} f_{l u}=(\lambda / 258.27)^{2} g_{u} A_{u l}$, where $g_{l(u)}$ is the statistical weight of the lower (upper) level, with $\lambda$ in nm and $A$ in (ns) $)^{-1}$.
However, some lines can be too weak to be measured, but the total BF of all missing lines can be estimated from theoretical calculations. This correction is called the residual and is given in Table A.1 for each level.

The niobium spectra where produced in a hollow cathode discharge with a mixture of neon and argon as carrier gas (at a current of $0.6 \mathrm{~A}$ and a pressure of 1 Torr), and recorded using the Lund Observatory Chelsea Instruments FT500 UV Fourier transform spectrometer, with a resolution of $0.035 \mathrm{~cm}^{-1}$. Two spectra were used. The first, covering the wavenumber region $20000-40000 \mathrm{~cm}^{-1}(250-500 \mathrm{~nm})$, was recorded with a Hamamatsu R955 optical photomultiplier tube. The second spectrum (28 000-56 $000 \mathrm{~cm}^{-1}, 180-360 \mathrm{~nm}$ ) was recorded with a Hamamatsu R166 solar blind photomultiplier tube. The spectra were intensity calibrated using branching ratios in argon (from 20000 to $35000 \mathrm{~cm}^{-1}, 290-500 \mathrm{~nm}$ ) reported by Whaling et al. (1993), and a deuterium lamp calibrated by Physicalisch-Technische Bundesanstalt, Berlin, Germany $\left(30000-50000 \mathrm{~cm}^{-1}\right.$, 200$330 \mathrm{~nm})$. The calibration procedure is further discussed in Sikström et al. (2002).

The uncertainties in the BFs include the uncertainty in the intensity measurements and the uncertainty in the intensity calibration, not only in the line itself, but also in the other lines from the same upper level, as they influence the derived value of the BF. The method to estimate uncertainties is described in detail in Sikström et al. (2002). The derived BFs and $\log (g f)$ values are given in Table A.1. The BFs are compared with theoretical values from this work and values from Kurucz (2017). In addition, we present the uncertainties both in the BFs and in the $g f$-values. The uncertainty in the $g f$-values includes the uncertainty both in the $\mathrm{BF}$ and the lifetime.

In most cases the lines were easy to identify thanks to the thorough analysis by Ryabtsev et al. (2000). However, we found a few lines that were blended or misidentified. The transition $4 d^{3}\left({ }^{4} F\right) 5 p^{5} F_{3}-4 d^{3}\left({ }^{4} F\right) 5 d^{5} P_{3}$ at $34748.346 \mathrm{~cm}^{-1}(287.7 \mathrm{~nm})$ is blended with a weak hfs pattern, as seen in Fig. 3. The intensity of the line is corrected by measuring the intensity of the adjacent hfs components to estimate the blending contribution. The correction changed the $\mathrm{BF}$ of this line from 0.40 to 0.35 .

The line at $25770.230 \mathrm{~cm}^{-1}(387.9 \mathrm{~nm})$ is identified by Ryabtsev et al. (2000) as $4 d^{3}\left({ }^{2} \mathrm{H}\right) 5 \mathrm{p}^{3} \mathrm{H}_{4}-4 \mathrm{~d}^{3}\left({ }^{4} \mathrm{~F}\right) 5 \mathrm{~d}{ }^{5} \mathrm{~F}_{5}$. However, as suggested by Nilsson et al. (2010), this is probably the 


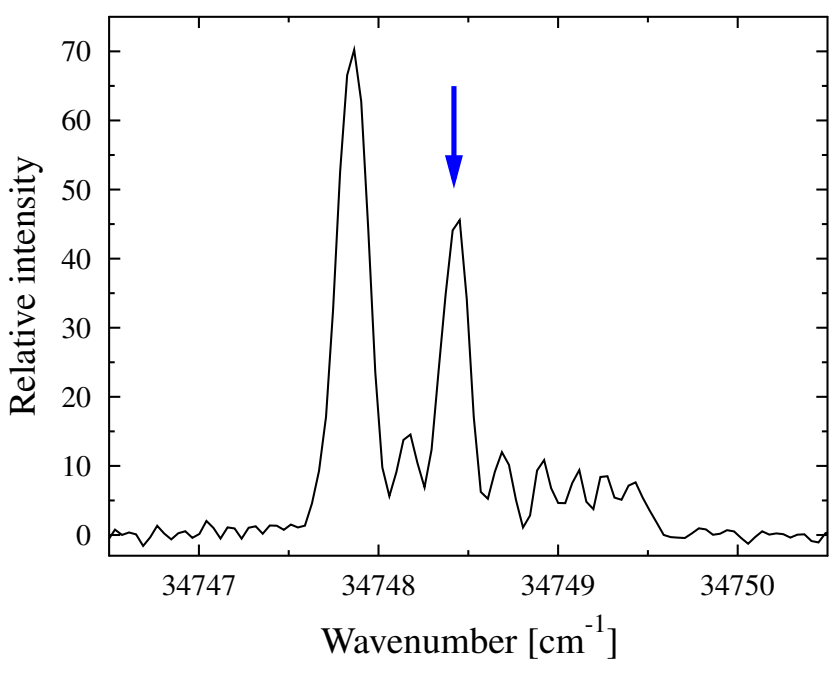

Fig. 3. $4 d^{3}\left({ }^{4} F\right) 5 p^{5} F_{3}-4 d^{3}\left({ }^{4} F\right) 5 d^{5} P_{3}$ transition, marked with the arrow. The line is blended with the wide hfs pattern of an unidentified line. The blending intensity is estimated with the adjacent hfs components (see text).

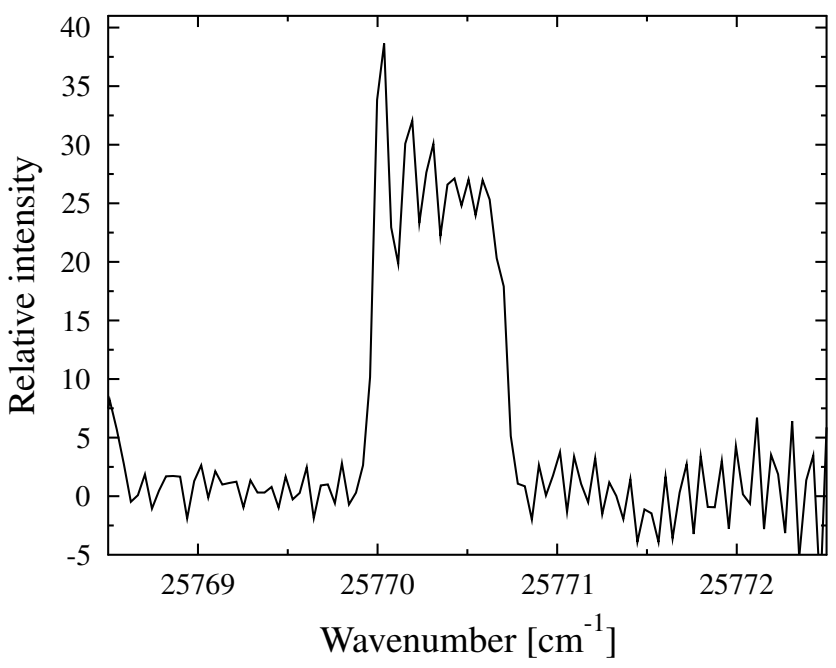

Fig. 4. $4 d^{4} a^{1} G_{4}-4 d^{3}\left({ }^{4} F\right) 5 p z^{3} F_{4}$ transition. The line is wrongly assigned as $4 d^{3}\left({ }^{2} \mathrm{H}\right) 5 p^{3} \mathrm{H}_{4}-4 \mathrm{~d}^{3}\left({ }^{4} \mathrm{~F}\right) 5 \mathrm{~d}^{5} \mathrm{~F}_{5}$ transition by Ryabtsev et al. (2000) (see text).

$4 d^{4} a^{1} G_{4}-4 d^{3}\left({ }^{4} F\right) 5 p z^{3} F_{4}$ transition instead, which has a Ritz wavenumber of $25770.263 \mathrm{~cm}^{-1}$. Furthermore, this identification is strengthened by analysing the hfs pattern (as can be seen in Fig. 4) of the line, which is consistent with the splittings in the two levels, $4 \mathrm{~d}^{4} \mathrm{a}^{1} \mathrm{G}_{4}$ and $4 \mathrm{~d}^{3}\left({ }^{4} \mathrm{~F}\right) 5 \mathrm{p} \mathrm{z}{ }^{3} \mathrm{~F}_{4}$, reported by Nilsson \& Ivarsson (2008).

The line at $32554.352 \mathrm{~cm}^{-1}(307.1 \mathrm{~nm})$ is identified by Ryabtsev et al. (2000) as $4 d^{3}\left({ }^{4} F\right) 5 p{ }^{3} F_{4}-4 d^{3}\left({ }^{4} F\right) 5 d{ }^{5} F_{5}$. However, this coincides with the $4 \mathrm{~d}^{4} \mathrm{a}^{1} \mathrm{G}_{4}-4 \mathrm{~d}^{3}\left({ }^{2} \mathrm{H}\right) 5 \mathrm{p}{ }^{3} \mathrm{H}_{4}$ transition (with the Ritz wavenumber $32554.359 \mathrm{~cm}^{-1}$ ) which, according to our calculations, has a transition probability that is orders of magnitude larger. We therefore conclude that the two lines $25770.230 \mathrm{~cm}^{-1}$ and $32554.352 \mathrm{~cm}^{-1}$ are misidentified by Ryabtsev et al. (2000), and we have excluded them in the analysis of the level $4 \mathrm{~d}^{3}\left({ }^{4} \mathrm{~F}\right) 5 \mathrm{~d}^{5} \mathrm{~F}_{5}$ at $73115.352 \mathrm{~cm}^{-1}$.

In most cases the residual is small (between 0.4 and $4.1 \%$ ). However, for the $4 \mathrm{~d}^{3}\left({ }^{4} \mathrm{~F}\right) 5 \mathrm{~d}{ }^{5} \mathrm{P}_{1}$ and $4 \mathrm{~d}^{3}\left({ }^{4} \mathrm{~F}\right) 5 \mathrm{~d}{ }^{5} \mathrm{~F}_{1}$ transitions, the residuals are larger 14.4 and $31.3 \%$, respectively). This is

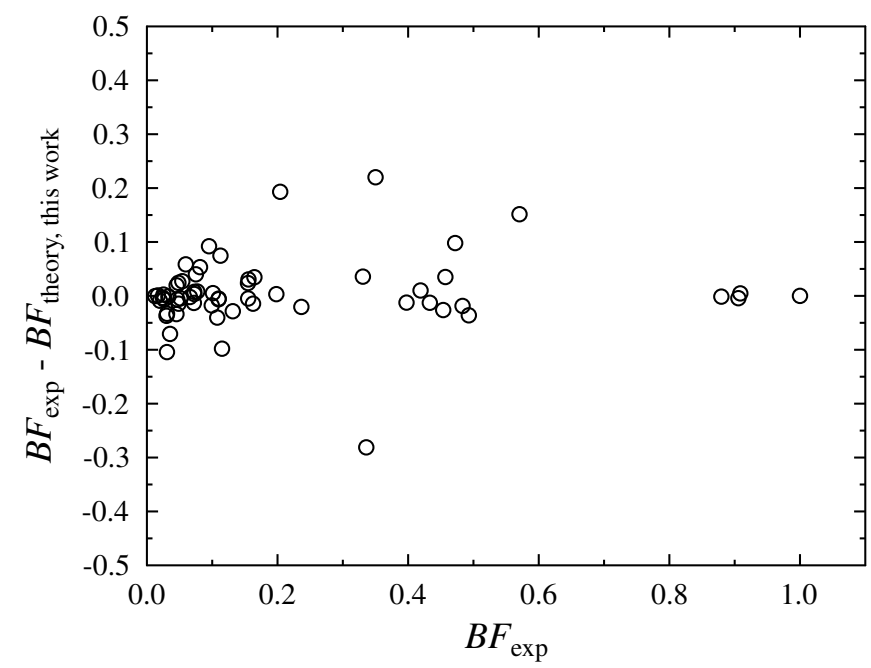

Fig. 5. Comparison between our experimental BFs and theoretical values.

because that the population is proportional to the statistical weight, $g=2 J+1$, so lines from levels with $J=1$ have a lower signal to noise ratio, and some of the lines therefore become too weak to be measured. However, the lines that are measured are in good agreement with the theoretical values, if scaled with the residual. The uncertainties for these two levels will perhaps be overestimated as the residual is given an uncertainty of $50 \%$.

For the levels $4 d^{3}\left({ }^{4} \mathrm{~F}\right) 5 \mathrm{~d}^{5} \mathrm{P}_{3}$ and $4 \mathrm{~d}^{3}\left({ }^{4} \mathrm{~F}\right) 5 \mathrm{~d}^{5} \mathrm{~F}_{3}$, both $J=3$, a poor agreement between experiment and theory is seen. We find no experimental reason for this, but it can be noted that the two different calculations are not in agreement for these two levels. Because of the poor agreement between experiment and theory we have not included residuals for these levels. This may overestimate the BFs from these levels slightly.

\section{Semi-empirical calculations}

The experimental radiative parameters measured in the present work are compared with theoretical results obtained using the pseudo-relativistic Hartree-Fock (HFR) method of Cowan (1981) modified to take core-polarization effects (HFR+CPOL) into account, as described fore example by Quinet et al. (1999, 2002). The calculations are based on the same physical model as the one assumed to be best (referred to as HFR(B)) in our previous work on $\mathrm{Nb}$ II (Nilsson et al. 2010). As a reminder, in this model the intravalence interactions were considered by explicitly including the following multi-configuration expansions: $4 \mathrm{~d}^{4}+$ $4 d^{3} 5 s+4 d^{3} 6 s+4 d^{3} 5 d+4 d^{2} 5 s^{2}+4 d^{2} 5 p^{2}+4 d^{2} 5 s 6 s+4 d^{2} 5 s 5 d$ $+4 d^{2} 4 f 5 p+4 d^{2} 5 p 5 f+4 d^{2} 6 s^{2}+4 d^{2} 5 d^{2}+4 d^{2} 5 d 6 s+4 d^{2} 5 p 6 p$ for the even parity, and $4 d^{3} 5 p+4 d^{3} 6 p+4 d^{3} 4 f+4 d^{3} 5 f+$ $4 d^{2} 5 s 5 p+4 d^{2} 5 s 6 p+4 d^{2} 4 f 5 s+4 d^{2} 4 f 5 d+4 d^{2} 5 s 5 f+4 d^{2} 5 p 6 s+$ $4 d^{2} 5 p 5 d+4 d^{2} 6 s 6 p$ for the odd parity. Using the well-established least-squares approach that minimizes the differences between the calculated and the available experimental energy levels published by Ryabtsev et al. (2000), some radial parameters were optimized according to the methodology described in detail by Nilsson et al. (2010). The core-polarization effects were first estimated using the dipole polarizability corresponding to the ionic $\mathrm{Nb}$ IV core given in Fraga et al. (1976), $\alpha_{\mathrm{d}}=5.80 a_{0}^{3}$, while the cut-off radius $\left(r_{\mathrm{c}}\right)$ was chosen to be the mean value $\langle r\rangle$ of the outermost $4 \mathrm{~d}$ core orbital, $r_{\mathrm{c}}=1.85 a_{0}$. Using these two parameters, we found that our calculated lifetimes were systematically 


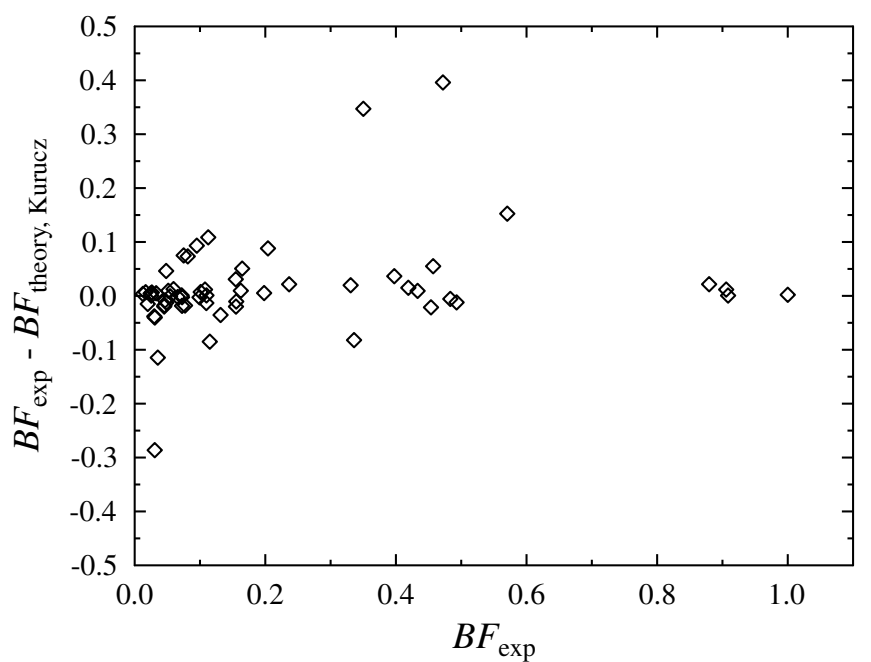

Fig. 6. Comparison between our experimental BFs and theoretical values from Kurucz (2017).

a few percent longer than those measured in the present work for $4 d^{3} 6 s$ and $4 d^{3} 5 d$ levels. Therefore, we adjusted semi-empirically the dipole radial integrals of the $4 d^{3} 5 p-4 d^{3} 6 s$ and $4 d^{3} 5 p-$ $4 d^{3} 5 d$ transitions to fit the calculations to the experimental lifetimes. This gave rise to the values $\langle 5 \mathrm{p}|\mathrm{r}| 6 \mathrm{~s}\rangle=-2.64$ a.u. and $\langle 5 \mathrm{p}|\mathrm{r}| 5 \mathrm{~d}\rangle=-5.74$ a.u., that being respectively $6 \%$ and $9 \%$ larger than the values obtained using the HFR(B) model considered in our previous paper (Nilsson et al. 2010).

The calculated lifetimes are compared with the experimental measurements in Table 1. We can clearly note that our calculated values fall within the experimental uncertainties, the average ratio $\tau_{\text {Calc }} / \tau_{\text {Exp }}$ being equal to $0.99 \pm 0.05$ where the uncertainty represents the standard deviation from the mean. This agreement is similar to (but slightly better than) the one obtained when comparing the theoretical data from Kurucz (2017) with the experimental lifetimes $\left(\tau_{\text {Kurucz }} / \tau_{\text {Exp }}=0.98 \pm 0.06\right)$. In Table A. 1 , the BFs calculated in the present work are compared with the experimental values and the theoretical results deduced from the work of Kurucz (2017). These comparisons are illustrated in Figs. 5 and 6 . It can be seen that our computed values are generally in better agreement with the experimental values (standard deviation $\Delta \sigma=0.067$ ) than those from Kurucz (2017) $(\Delta \sigma=0.089)$. However, for two upper even levels, those located at 72125.247 and $72183.090 \mathrm{~cm}^{-1}$, rather large discrepancies (up to two orders of magnitude) are observed when comparing the theoretical BFs with the measurements. This is mainly due to the strong mixings characterizing not only the upper but also the lower levels involved in the transitions. More precisely, according to our calculations, the main LS components of the levels at 72125.247 and $72183.090 \mathrm{~cm}^{-1}$ are $81 \% 5 \mathrm{~d}^{5} \mathrm{P}_{3}+13 \% 5 \mathrm{~d}$ ${ }^{3} \mathrm{D}_{3}+2 \% 5 \mathrm{~d}^{5} \mathrm{~F}_{3}$ and $60 \% 5 \mathrm{~d}^{5} \mathrm{~F}_{3}+33 \% 5 \mathrm{~d}^{5} \mathrm{G}_{3}+2 \% 5 \mathrm{~d}^{3} \mathrm{D}_{3}$, respectively. Both of them have, for example, one transition to the $5 \mathrm{p}{ }^{5} \mathrm{~F}_{3}$ lower level $\left(E=37376.901 \mathrm{~cm}^{-1}\right)$, for which the theoretical and experimental BFs disagree. In fact, for this latter level, our calculations give a strongly mixed eigenvector, $53 \%$ $5 p^{5} \mathrm{~F}_{3}+25 \% 5 \mathrm{p}^{3} \mathrm{D}_{3}+7 \% 5{ }^{5} \mathrm{D}_{3}$, giving rise to transition decay rates for the lines at 2876.991 and $2872.209 \AA$, which are very sensitive to small changes in the eigenvector compositions, both for the upper $5 \mathrm{~d}$ and lower $5 \mathrm{p}$ levels. Moreover, both levels at 72125.247 and $72183.090 \mathrm{~cm}^{-1}$ are depopulated by quite a large number of very weak lines (contributing to the residuals given in Table A.1), which are affected by strong cancellation effects in our calculations (see Cowan 1981). This makes the determination of BFs less reliable for these two levels.

\section{Summary}

We report experimental and theoretical radiative lifetimes for high lying even $4 d^{3} 5 d$ and 6 s levels, between 68000 and $73200 \mathrm{~cm}^{-1}$ in $\mathrm{Nb}$ II. In addition, we have measured BFs for 59 lines depopulating the levels. Combing the lifetimes with the BFs has generated absolute transition probabilities for the lines. The experimental values are compared with theoretical data, both new data reported in this work and values from the literature (Kurucz 2017).

Acknowledgements. This work was supported by the Swedish Research Council through the Linnaeus grant to the Lund Laser Centre and the Knut and Alice Wallenberg Foundation. This work was financially supported by the Integrated Initiative of Infrastructure Project LASERLAB-EUROPE, contract LLC002130. H.H acknowledges the Swedish Research Council Grant 2016-04185. P.P. and P.Q. are respectively Research Associate and Research Director of the Belgian Fund for Scientific Research F.R.S.-FNRS. Financial support from this organization is sincerely acknowledged.

\section{References}

Corliss, C. H., \& Bozman, W. R. 1962, Natl. Bur. Stand. (US) Monogr., 53 (Washington, D.C.: US Department of Commerce)

Cowan, R. D. 1981, The Theory of Atomic Structure and Spectra (Berkeley: Univ. California Press)

Engström, L., Lundberg, H., Nilsson, H., Hartman, H., \& Bäckström, E. 2014, A\&A, 570, A34

Fraga, S., Karwowski, J., \& Saxena, K. M. S. 1976, Handbook of Atomic Data (Amsterdam: Elsevier)

Griffith, W. P., \& Morris, P. J. T. 2003, Notes Rec. R. Soc. Lond., 57, 299

Hannaford, P., Lowe, R. M., Biemont, E., \& Grevesse, N. 1985, A\&A, 143, 447

Humpreys, C. J., \& Meggers, W. F. 1945, Res. Nat. Bur. Stand. (U.S.), 43, 481

Iglesias, L. 1954, An. Real Soc. Esp. Fys. Quim. (Madrid), 50, 135

Kurucz, R. L. 2017, Available at http: //kurucz .harvard.edu/atoms .html [accessed June 18]

Lundberg, H., Hartman, H., Engström, L., et al. 2016, MNRAS, 460, 356

Meggers, W. F., \& Schribner, B. F. 1935, J. Res. Natl. Bur. Stand. (U.S.), 14, 629

Mills, I., Cvitas, T., Homann, K., Kallay, N., \& Kuchitsu, K. 1988, Quantities, Units and Symbols in Physical Chemistry (Oxford, UK: Blackwell Scientific Publications) [Copyright 1988 IUPAC]

Nilsson, H., \& Ivarsson, S. 2008, A\&A, 492, 609

Nilsson, H., Hartman, H., Engström, L., et al. 2010, A\&A, 511, A16

Neyskens, P., Van Eck, S., Jorissen, A., et al. 2015, Nature, 517, 174

Palmeri, P., Quinet, P., Fivet, V., et al. 2008, Phys. Scr., 78, 015304

Quinet, P., Palmeri, P., Biémont, E., et al. 1999, MNRAS, 307, 934

Quinet, P., Palmeri, P., Biémont, E., et al. 2002, J. Alloys Comp., 344, 255

Ryabtsev, A. N., Churilov, S. S., \& Litzén, U. 2000, Phys. Scr., 62, 368

Sikström, C. M., Nilsson, H., Litzén, U., Blom, A., \& Lundberg, H. 2002, J. Quant. Spectrosc. Radiat. Transfer, 74, 355

Smith, V. V., \& Lambert, D. L. 1984, Publ. Astron. Soc. Pac., 96, 226

Whaling, W., Carle, M. T., \& Pitt, M. L. 1993, J. Quant. Spec. Radiat. Transf., 50,7

Young, L., Hasegawa, S., Kurtz, C., Datta, D., \& Beck, D. R. 1995, Phys. Rev. A, 51, 3534 


\section{Appendix A: Additional table}

Table A.1. Experimental and theoretical branching fractions for transitions in Nb II.

\begin{tabular}{|c|c|c|c|c|c|c|c|c|c|}
\hline \multirow{2}{*}{$\begin{array}{l}\text { Upper } \\
\text { level }{ }^{(a)}\left[\mathrm{cm}^{-1}\right]\end{array}$} & \multirow{2}{*}{$\begin{array}{l}\text { Lower } \\
\text { level }{ }^{(a)}\end{array}$} & \multirow[t]{2}{*}{$\lambda_{\text {air }}{ }^{(a)}[\AA]$} & \multirow[t]{2}{*}{$\sigma^{(a)}\left[\mathrm{cm}^{-1}\right]$} & \multirow[t]{2}{*}{$\mathrm{BF}_{\exp }$} & \multirow{2}{*}{$\begin{array}{l}\text { Unc } \\
{[\%]}\end{array}$} & \multicolumn{2}{|c|}{$B F_{\text {theory }}$} & \multirow[t]{2}{*}{$\log (g f)_{\exp }$} & \multirow{2}{*}{$\begin{array}{r}\mathrm{Unc}_{g f} \\
{[\%]}\end{array}$} \\
\hline & & & & & & This work & Kurucz $^{(b)}$ & & \\
\hline $6 s e^{5} F_{5}$ & $5 p^{5} \mathrm{G}_{5}$ & 3002.242 & 33298.731 & 0.0485 & 15 & 0.063 & 0.061 & -0.549 & 16 \\
\hline \multirow{5}{*}{$E=68772.928$} & $5 p^{5} G_{6}$ & 3093.403 & 32317.471 & 0.5705 & 4 & 0.419 & 0.418 & 0.548 & 5 \\
\hline & $5 p^{5} F_{4}$ & 3199.634 & 31244.546 & 0.0308 & 16 & 0.064 & 0.071 & -0.691 & 17 \\
\hline & $5 \mathrm{p}^{5} \mathrm{~F}_{5}$ & 3251.244 & 30748.592 & 0.1982 & 12 & 0.195 & 0.193 & 0.132 & 12 \\
\hline & $5 p^{5} D_{4}$ & 3279.714 & 30481.676 & 0.1150 & 12 & 0.213 & 0.200 & -0.097 & 13 \\
\hline & $5 p^{3} G_{5}$ & 3396.035 & 28669.323 & 0.0200 & 17 & 0.029 & 0.035 & -0.826 & 18 \\
\hline Residual & & & & & & 0.017 & & & \\
\hline $5 \mathrm{~d} \mathrm{e} \mathrm{e}_{3}$ & $5 p{ }^{5} G_{2}$ & 2662.720 & 37544.414 & 0.9086 & 1 & 0.904 & 0.908 & 0.612 & 12 \\
\hline$E=70895.504$ & $5 p^{5} G_{3}$ & 2703.636 & 36976.260 & 0.0514 & 7 & 0.056 & 0.042 & -0.621 & 14 \\
\hline Residual & & & & & & 0.041 & & & \\
\hline \multirow[t]{2}{*}{$5 d \mathrm{e}^{5} \mathrm{P}_{1}$} & $5 p^{3} D_{1}$ & 2771.597 & 36069.627 & $\mathrm{BL}$ & & 0.078 & 0.135 & & \\
\hline & $5 \mathrm{p}^{5} \mathrm{D}_{0}$ & 2970.218 & 33657.739 & 0.1625 & 18 & 0.177 & 0.153 & -0.513 & 20 \\
\hline \multirow[t]{2}{*}{$E=70995.981$} & $5 p^{5} D_{1}$ & 2986.352 & 33475.905 & 0.4570 & 12 & 0.422 & 0.402 & -0.059 & 14 \\
\hline & $5 p^{5} D_{2}$ & 3014.925 & 33158.665 & 0.2365 & 16 & 0.257 & 0.215 & -0.337 & 17 \\
\hline Residual & & & & & & 0.144 & & & \\
\hline \multirow{3}{*}{$\begin{array}{l}5 \mathrm{~d} \mathrm{e}^{5} \mathrm{~F}_{1} \\
E=71196.067\end{array}$} & $5 p^{3} D_{1}$ & 2753.270 & 36309.713 & 0.4332 & 16 & 0.446 & 0.424 & -0.173 & 18 \\
\hline & $5 p^{3} D_{2}$ & 2802.238 & 35675.245 & 0.0993 & 18 & 0.117 & 0.102 & -0.797 & 19 \\
\hline & $5 p^{5} D_{0}$ & 2949.180 & 33897.825 & 0.1555 & 22 & 0.125 & 0.166 & -0.558 & 23 \\
\hline Residual & & & & & & 0.313 & & & \\
\hline \multirow{4}{*}{$\begin{array}{l}5 \mathrm{~d} \mathrm{e}^{5} \mathrm{H}_{5} \\
E=71684.873\end{array}$} & $5 p^{5} G_{4}$ & 2698.048 & 37052.967 & 0.8796 & 1 & 0.881 & 0.858 & 0.734 & 8 \\
\hline & $5 p^{5} G_{5}$ & 2760.801 & 36210.803 & 0.0263 & 7 & 0.033 & 0.020 & -0.771 & 10 \\
\hline & $5 p^{5} F_{4}$ & 2926.845 & 34156.618 & 0.0771 & 7 & 0.069 & 0.095 & -0.253 & 11 \\
\hline & & & & & & 0.018 & & & \\
\hline \multirow{8}{*}{$\begin{array}{l}5 \mathrm{~d} \mathrm{e}^{5} \mathrm{P}_{3} \\
E=72125.247\end{array}$} & $5 p^{5} \mathrm{G}_{4}$ & 2666.356 & 37493.214 & 0.0595 & 6 & 0.001 & 0.047 & -0.654 & 10 \\
\hline & $5 \mathrm{p}^{3} \mathrm{D}_{2}$ & 2731.102 & 36604.425 & 0.0813 & 6 & 0.028 & 0.008 & -0.497 & 10 \\
\hline & $5 p^{5} F_{2}$ & 2843.105 & 35162.473 & 0.0126 & 22 & 0.013 & 0.009 & -1.273 & 23 \\
\hline & $5 p^{5} F_{3}$ & 2876.991 & 34748.346 & $0.3501^{(c)}$ & 15 & 0.130 & 0.003 & 0.182 & 17 \\
\hline & $5 \mathrm{p}^{5} \mathrm{~F}_{4}$ & 2889.588 & 34596.865 & 0.0482 & 9 & 0.024 & 0.002 & -0.676 & 12 \\
\hline & $5 p^{5} D_{2}$ & 2912.227 & 34327.931 & 0.1126 & 7 & 0.038 & 0.004 & -0.300 & 10 \\
\hline & $5 p^{5} D_{4}$ & 2954.744 & 33833.995 & 0.3359 & 6 & 0.617 & 0.418 & 0.187 & 10 \\
\hline & & & & & & 0.150 & & & \\
\hline \multirow{8}{*}{$\begin{array}{l}5 \mathrm{~d} \mathrm{e}^{5} \mathrm{~F}_{3} \\
E=72183.090\end{array}$} & $5 p^{5} G_{3}$ & 2612.653 & 38263.846 & 0.0452 & 3 & 0.079 & 0.065 & -0.811 & 8 \\
\hline & $5 \mathrm{p}^{5} \mathrm{G}_{4}$ & 2662.249 & 37551.057 & 0.1077 & 3 & 0.148 & 0.096 & -0.417 & 8 \\
\hline & $5 \mathrm{p}^{3} \mathrm{D}_{3}$ & 2805.809 & 35629.852 & 0.4720 & 2 & 0.374 & 0.076 & 0.270 & 8 \\
\hline & $5 p^{5} F_{3}$ & 2872.209 & 34806.189 & 0.0307 & 12 & 0.135 & 0.317 & -0.896 & 14 \\
\hline & $5 \mathrm{p}^{5} \mathrm{~F}_{4}$ & 2884.765 & 34654.708 & 0.0300 & 12 & 0.067 & 0.068 & -0.903 & 14 \\
\hline & $5 p^{5} D_{2}$ & 2907.328 & 34385.774 & 0.0354 & 13 & 0.106 & 0.150 & -0.824 & 15 \\
\hline & $5 \mathrm{p}^{5} \mathrm{D}_{3}$ & 2943.199 & 33966.703 & 0.0750 & 9 & 0.035 & 0.000 & -0.487 & 12 \\
\hline & $5 \mathrm{p}^{5} \mathrm{D}_{4}$ & 2949.701 & 33891.838 & 0.2041 & 5 & 0.011 & 0.116 & -0.051 & 9 \\
\hline Residual $^{(d)}$ & & & & & & 0.045 & & & \\
\hline \multirow{3}{*}{$\begin{array}{l}5 \mathrm{~d} \mathrm{e}^{5} \mathrm{H}_{6} \\
E=72231.658\end{array}$} & $5 p^{5} G_{5}$ & 2719.730 & 36757.461 & 0.9057 & 1 & 0.910 & 0.894 & 0.826 & 8 \\
\hline & $5 \mathrm{p}^{5} \mathrm{G}_{6}$ & 2794.330 & 35776.201 & 0.0168 & 8 & 0.016 & 0.010 & -0.883 & 11 \\
\hline & $5 p^{5} \mathrm{~F}_{5}$ & 2922.495 & 34207.322 & 0.0725 & 7 & 0.069 & 0.091 & -0.208 & 11 \\
\hline Residual & & & & & & 0.004 & & & \\
\hline
\end{tabular}

Notes. ${ }^{(c)}$ Corrected for blend (see text). ${ }^{(d)}$ Residual not included in these levels (see text).

References. ${ }^{(a)}$ Ryabtsev et al. (2000). ${ }^{(b)}$ Kurucz (2017). 
H. Nilsson et al.: Experimental and theoretical lifetimes and transition probabilities for spectral lines in $\mathrm{Nb}$ II

Table A.2. continued.

\begin{tabular}{|c|c|c|c|c|c|c|c|c|c|}
\hline \multirow{2}{*}{$\begin{array}{l}\text { Upper } \\
\text { level }^{(a)}\left[\mathrm{cm}^{-1}\right]\end{array}$} & \multirow{2}{*}{$\begin{array}{l}\text { Lower } \\
\text { level }^{(a)}\end{array}$} & \multirow[t]{2}{*}{$\lambda_{\text {air }}{ }^{(a)}[\AA]$} & \multirow[t]{2}{*}{$\sigma^{(a)}\left[\mathrm{cm}^{-1}\right]$} & \multirow[t]{2}{*}{$\mathrm{BF}_{\exp }$} & \multirow{2}{*}{$\begin{array}{l}\text { Unc } \\
{[\%]}\end{array}$} & \multicolumn{2}{|c|}{$B F_{\text {theory }}$} & \multirow[t]{2}{*}{$\log (g f)_{\exp }$} & \multirow{2}{*}{$\begin{array}{r}\mathrm{Unc}_{g f} \\
{[\%]}\end{array}$} \\
\hline & & & & & & This work & Kurucz $^{(b)}$ & & \\
\hline $\begin{array}{l}5 \mathrm{~d} \mathrm{e}^{5} \mathrm{G}_{5} \\
E=72460.669\end{array}$ & $\begin{array}{l}5 p^{5} G_{4} \\
5 p^{5} G_{5} \\
5 p^{5} F_{4} \\
5 p^{5} F_{5} \\
5 p^{5} D_{4}\end{array}$ & $\begin{array}{l}2642.713 \\
2702.889 \\
2861.841 \\
2903.059 \\
2925.737\end{array}$ & $\begin{array}{l}37828.636 \\
36986.472 \\
34932.287 \\
34436.333 \\
34169.417\end{array}$ & $\begin{array}{l}0.0455 \\
0.3307 \\
0.3975 \\
0.0719 \\
0.1315\end{array}$ & $\begin{array}{l}4 \\
3 \\
3 \\
5 \\
4\end{array}$ & $\begin{array}{l}0.026 \\
0.295 \\
0.410 \\
0.085 \\
0.160 \\
0.024 \\
\end{array}$ & $\begin{array}{l}0.063 \\
0.311 \\
0.361 \\
0.071 \\
0.167\end{array}$ & $\begin{array}{r}-0.613 \\
0.278 \\
0.408 \\
-0.323 \\
-0.053\end{array}$ & $\begin{array}{l}10 \\
10 \\
10 \\
11 \\
10\end{array}$ \\
\hline $\begin{array}{l}5 \mathrm{~d} \mathrm{e}^{5} \mathrm{~F}_{4} \\
E=72624.931\end{array}$ & $\begin{array}{l}5 p^{5} \mathrm{G}_{4} \\
5 p^{5} \mathrm{G}_{5} \\
5 \mathrm{p}^{3} \mathrm{D}_{3} \\
5 \mathrm{p}{ }^{5} \mathrm{~F}_{4} \\
5 \mathrm{p}{ }^{5} \mathrm{~F}_{5} \\
5 p{ }^{5} \mathrm{D}_{3} \\
5 \mathrm{p}^{3} \mathrm{G}_{4}\end{array}$ & $\begin{array}{l}2631.286 \\
2690.938 \\
2771.439 \\
2848.446 \\
2889.276 \\
2905.404 \\
3003.060\end{array}$ & $\begin{array}{l}37992.898 \\
37150.734 \\
36071.693 \\
35096.549 \\
34600.595 \\
34408.544 \\
33289.661\end{array}$ & $\begin{array}{l}0.1099 \\
0.1548 \\
0.0725 \\
0.4833 \\
0.0244 \\
0.1097 \\
0.0254\end{array}$ & $\begin{array}{r}3 \\
3 \\
4 \\
2 \\
9 \\
4 \\
14\end{array}$ & $\begin{array}{l}0.115 \\
0.131 \\
0.065 \\
0.502 \\
0.028 \\
0.116 \\
0.023 \\
0.020 \\
\end{array}$ & $\begin{array}{l}0.109 \\
0.124 \\
0.075 \\
0.489 \\
0.020 \\
0.123 \\
0.025\end{array}$ & $\begin{array}{r}-0.289 \\
-0.121 \\
-0.425 \\
0.423 \\
-0.862 \\
-0.204 \\
-0.811\end{array}$ & $\begin{array}{r}8 \\
8 \\
8 \\
8 \\
12 \\
9 \\
16\end{array}$ \\
\hline $\begin{array}{l}5 \mathrm{~d} \mathrm{e}^{5} \mathrm{H}_{7} \\
E=72861.270 \\
\text { Residual }\end{array}$ & $5 p^{5} G_{6}$ & 2746.002 & 36405.813 & 1.0000 & & $\begin{array}{l}1.000 \\
0.000\end{array}$ & 0.998 & 0.987 & 6 \\
\hline $\begin{array}{l}5 \mathrm{de}^{5} \mathrm{~F}_{5} \\
E=73115.352\end{array}$ & $\begin{array}{l}5 p^{5} \mathrm{G}_{5} \\
5 \mathrm{p}^{5} \mathrm{G}_{6} \\
5 \mathrm{p}^{5} \mathrm{~F}_{4} \\
5 \mathrm{p}^{5} \mathrm{~F}_{5} \\
5 \mathrm{p}^{5} \mathrm{D}_{4} \\
5 \mathrm{p}^{3} \mathrm{G}_{5}\end{array}$ & $\begin{array}{l}2655.876 \\
2726.969 \\
2809.190 \\
2848.895 \\
2870.732 \\
3028.343\end{array}$ & $\begin{array}{l}37641.073 \\
36659.813 \\
35586.888 \\
35090.934 \\
34824.018 \\
33011.665\end{array}$ & $\begin{array}{l}0.1646 \\
0.1011 \\
0.0659 \\
0.4537 \\
0.1551 \\
0.0465\end{array}$ & $\begin{array}{r}3 \\
3 \\
4 \\
2 \\
4 \\
16\end{array}$ & $\begin{array}{l}0.130 \\
0.096 \\
0.068 \\
0.480 \\
0.160 \\
0.053 \\
0.013 \\
\end{array}$ & $\begin{array}{l}0.114 \\
0.094 \\
0.068 \\
0.475 \\
0.175 \\
0.055\end{array}$ & $\begin{array}{r}-0.008 \\
-0.196 \\
-0.357 \\
0.494 \\
0.034 \\
-0.442\end{array}$ & $\begin{array}{r}8 \\
8 \\
9 \\
8 \\
9 \\
18\end{array}$ \\
\hline $\begin{array}{l}5 \mathrm{~d} \mathrm{e}^{5} \mathrm{G}_{6} \\
E=73161.143\end{array}$ & $\begin{array}{l}5 p{ }^{5} \mathrm{G}_{5} \\
5 \mathrm{p}^{5} \mathrm{G}_{6} \\
5 \mathrm{p}^{5} \mathrm{~F}_{5} \\
5 \mathrm{p}^{3} \mathrm{G}_{5}\end{array}$ & $\begin{array}{l}2652.649 \\
2723.567 \\
2845.182 \\
3024.148\end{array}$ & $\begin{array}{l}37686.946 \\
36705.686 \\
35136.807 \\
33057.538\end{array}$ & $\begin{array}{l}0.0542 \\
0.4190 \\
0.4929 \\
0.0329\end{array}$ & $\begin{array}{r}4 \\
3 \\
3 \\
14\end{array}$ & $\begin{array}{l}0.027 \\
0.409 \\
0.529 \\
0.034 \\
0.011\end{array}$ & $\begin{array}{l}0.055 \\
0.404 \\
0.505 \\
0.028\end{array}$ & $\begin{array}{r}-0.451 \\
0.460 \\
0.569 \\
-0.554\end{array}$ & $\begin{array}{l}10 \\
10 \\
10 \\
17\end{array}$ \\
\hline
\end{tabular}

